\title{
Plasmatic estradiol concentration in the mid-luteal phase is a good prognostic factor for clinical and ongoing pregnancies, during stimulated cycles of in vitro fertilization
}

\author{
Rodopiano S. Florêncio1, Melaynne S. B. Meira², Marcos V. da Cunha², Mylena N. C. R. Camarço ${ }^{1}$, Eduardo C. \\ Castro $^{1}$, Marta C. C. F. Finotti ${ }^{1}$, Vinicius A. de Oliveira ${ }^{1}$ \\ ${ }^{1}$ Humana Medicina Reprodutiva - Goiania, GO \\ 2 Medicine School, Federal University of Goias
}

This study was partially presented in CBRA 2014, Salvador, Bahia, Brazil.

\begin{abstract}
Objective: To evaluate the predictive efficiency of serum estradiol $\left(E_{2}\right)$ concentration in the mid-luteal phase regarding chemical, clinical, and ongoing pregnancies, in patients subjected to IVF/ICSI with fresh embryo transfer.

Methods: One hundred and forty-three patients undergoing IVF/ICSI met all the inclusion criteria for the present study. Most of the patients used antagonists, final maturation was achieved with recombinant chorionic gonadotrophin (HCG), and embryo transfer took place on days 3 to 5 , but mostly on day 4 . The luteal phase was supplemented with estradiol valerate $6 \mathrm{mg} /$ day and vaginal micronized progesterone $600 \mathrm{mg} /$ day. There was no exclusion of patients in the embryo transfer group due to age or ovarian reserve. All patients with estradiol and chorionic gonadotrophin ( $\beta \mathrm{HCG}$ ) dosage on the day of transfer, day 7 , were included. We assessed the following variables, initially regarding age: number of eggs collected, formed embryos, embryos transferred, day of transfer, transfer type, estradiol and chorionic gonadotropin. Next, we evaluated these elements at three different ranges of estradiol concentrations $(<200 \mathrm{pg} / \mathrm{ml}, 200-500 \mathrm{pg} / \mathrm{ml}$, and $>500$ $\mathrm{pg} / \mathrm{ml}$ ), comparing these parameters in pregnant $(P)$ and non-pregnant (NP) patients.
\end{abstract}

Results: Data analysis by age group in P and NP patients showed significant differences in the mean values of the variables $E_{2}$ and $\beta H C G, T D 7$. Mean serum estradiol levels in $\mathrm{P}$ and NP in the three age groups were: $<35$ years, $835 / 417 p=0.0006,35-39$ years $833 / 434 p=0.0118,>39$ years, $841 / 394 p=0.0012$. There was also a significant difference in pregnancy rates in the group $>500 \mathrm{pg} / \mathrm{ml}$ of estradiol concentration $(63.4 \%, p=0.0096)$. The likelihood of chemical and clinical abortions for the estradiol ranges were: $38.46 \%$, involving the two first ranges versus $15.15 \%$ for a concentration $>500 \mathrm{pg} / \mathrm{ml}, p=0.0412$ and $5.26 \%$ for a concentration $>900 \mathrm{pg} / \mathrm{ml}, p=0.0105$. The Pearson correlation coefficient for HCG and estradiol was $r=0.5108$.

Conclusion: This study showed the prognostic value of $\mathrm{E}_{2}$ in the mid-luteal phase (TD7) for chemical, clinical, and ongoing pregnancies, and its concentration suggested that there is a moderately positive correlation with $\beta$ HCG levels.

Keywords: In vitro fertilization, estradiol in the luteal phase, mid-luteal phase, luteal phase support

\section{INTRODUCTION}

Assisted reproduction treatments have achieved important positive results in recent years. Researches have evaluated several success factors that might interfere with the outcomes to help professionals achieve a better understanding of the whole process and improve it. Among those factors, serum estradiol concentration, both in the follicular phase (the initial phase or the day of chorionic gonadotrophin (HCG) administration for final maturation), and the mid-luteal phase have been investigated.

Some authors have investigated early follicular estradiol levels as a prognostic factor for pregnancy in cycles induced for in vitro fertilization, with or without intracytoplasmic sperm injection (IVF/ICSI). Moreover, such studies only used the agonist to block pituitary activity (Phelps et al., 1998; Khalaf et al., 2000). Studies with estradiol on the HCG day have not found any prognostic value (Erzincan et al., 2014; Huang et al., 2015). Another way of evaluating estradiol concentration $\left(E_{2}\right)$ as a prognostic tool is to calculate the rate of estradiol, comparing it on the day of HCG administration with the level obtained in the mid-luteal phase. Sharara et al. (2001) postulated that $E_{2}$ ratios $>5$ could compromise endometrial quality. Hung Yu $\mathrm{Ng}$ et al. (2000) found no statistical difference in pregnancy rates with $E_{2}$ ratios $\geq 5$ or below this level. Several authors studied the variation and average serum $E_{2}$ during luteal phases in natural cycles (Lenton et al., 1982; Baird et al., 1997) and induced cycles for IVF/ICSI after the pituitary activity was blocked (Hutchinson-Williams et al., 1989; Balasch et al., 1995, Aktan et al., 2004; Friedler et al., 2005; Ganesh et al., 2008). These authors suggested that serum $E_{2}$ levels in the luteal phase were higher when pregnancy occurred, as a reflection of trophoblastic gonadotropin (HCG) production in natural or induced cycles. In addition, Balasch et al. (1995) and Csemiczky et al. (1996) found a strong predictive value for clinical and ongoing pregnancies in relation to this hormone in the mid-luteal phase.

Greb et al. (2004) demonstrated that $\mathrm{E}_{2}$ levels behaved distinctly when comparing conceptive and nonconceptive cycles on day 4 after embryo transfer (TD4), and that the mean value was higher until day 14 . They reported that, in pregnant $(P)$ cycles, although $E_{2}$ levels start to increase on TD4, it was more evident on TD6; whereas in NP cycles its level was decreased. They also reported that in the luteal phase of cycles supplemented with HCG, $E_{2}$ values were fixed as of TD6, and there were no cases of $\mathrm{E}_{2}$ alterations. Ganesh et al. (2008) compared the levels of $E_{2}$ in $P$ and non-pregnant (NP) patients on days 0,7 and 14 in relation to TD after the IVF/ICSI procedure. They found similar $E_{2}$ values on day 0 for both $P$ and NP, and significantly higher levels for $P$ on days 7 and 14 . Hung $Y u ~ N g$ et al. (2000) compared the mean level of $E_{2}$ on TD6, and they reported that in cycles with HCG in the luteal phase, $\mathrm{E}_{2}$ concentrations were not significantly different in the two groups. Fatemi et al. (2007) reported that the addition of $4 \mathrm{mg} /$ day of $\mathrm{E}_{2}$ to progesterone in the luteal phase, produced higher levels of $E_{2}$ on TD5. Despite these apparent evidences of the prognostic value of $E_{2}$ in the luteal phase, the authors did not mention the benefits regarding the 
likelihood of pregnancy through the systematic use of $E_{2}$ on different routes of administration (Zegers-Hochschild \& Altieri, 1995; Fatemi et al., 2006; Engmann et al., 2008; Serna et al., 2008, Gelbaya et al., 2008). The estradiol concentration would only be a consequence of embryonic implantation, resulting in HCG production. Other authors (Gorkemli et al., 2004; Lukaszuk et al., 2005, Kutlusoy et al., 2014) have found statistical significant differences in pregnancy likelihood with the addition of $E_{2}$ or high doses of phytoestrogens to progesterone. Fujimoto et al. (2002) found a prognostic value of $E_{2}$ levels above $500 \mathrm{pg} / \mathrm{ml}$, with a significant higher pregnancy likelihood. In addition, they showed that $E_{2}$ values below $100 \mathrm{pg} / \mathrm{ml}$ during the mid-luteal phase meant lower pregnancy likelihood and this could be fixed in a later cycle using HCG associated with progesterone. DiLuigi et al. (2010) suggested that $\mathrm{E}_{2}$ concentrations in the luteal phase should be kept above $200 \mathrm{pg} /$ $\mathrm{ml}$ in patients who used agonist for final maturation with estradiol and progesterone supplementation.

These findings motivated us to evaluate our data retrospectively to determine whether $E_{2}$ concentrations 7 days after embryo transfer (TD7) in $\mathrm{P}$ and NP patients within three age groups and three different $E_{2}$ concentration ranges, from patients subjected to IVF/ICSI procedures, would be associated to chemical, clinical, and ongoing pregnancies.

\section{MATERIAL AND METHODS}

One hundred and forty-three patients underwent ovulation induction by controlled ovarian hyperstimulation for IVF/ICSI from January 2010 to December 2012 due to artificial insemination failures, ovarian endometriosis and/or deep endometriosis, post-infection tubal factor infertility or salpingectomy, male factor infertility indicated by the ejaculate analysis, or post epididymitis or testicular biopsy.

All patients signed an informed consent form for anonymous retrospective data analysis.

Inclusion criteria: 1- Patients subjected to IVF/ICSI and transfer of fresh embryos aged between 23 and 45 years. Patients followed by the same examiner at all clinical stages, represented $20 \%$ of all procedures performed in the clinic during the study period. We included patients with low, normal, or high ovarian reserve who underwent routine hormonal dosages in the luteal phase.

Exclusion Criteria: 1- Egg recipients 2- Incomplete or missing medical exams.

In summary, IVF/ICSI cycles consisted of: priming with oral contraceptive pills in the pre-induction period for 12 to 21 days. We performed basal ultrasound scan on the last day of the pill, or at the beginning of the menstrual cycle. Ovulation induction was performed with recombinant or urinary gonadotropin in all patients in a 150 to 300 IU daily dose starting on the $2^{\text {nd }}$ day of the cycle. In the agonist group, we used $0.05 \mathrm{ml}$ of subcutaneous leuprolide acetate (Lupron $\mathrm{Kit}^{\circledR}$ ) daily, starting 4 days before the pill administration was interrupted. It was reduced to half of the initial dose after 7 days of treatment. In the antagonist group, we used subcutaneous administration of Cetrorelix (Cetrotide ${ }^{\circledR}$ ) or Ganirelix (Orgalutran ${ }^{\circledR}$ ), in a flexible regimen when follicles reached $12-14 \mathrm{~mm}$ of average diameter. When follicles reached a mean diameter of 19 to $20 \mathrm{~mm}$, we administered recombinant chorionic gonadotrophin 250 mcg (Ovidrel ${ }^{\circledR}$ ) or agonists $(0.4 \mathrm{ml}$ leuprolide acetate or $0.2 \mathrm{mg}$ triptorelin) for those patients with ovarian hyperstimulation syndrome (OHSS) risk. The collection was performed 35-36 hours after HCG or leuprolide acetate injection, in most cases manually, and in a small number of cases with a medical suction pump. The eggs were injected 2 to 3 hours post collection or inseminated, in some cases of excellent semen quality. Fertilization was assessed after
19-22 hours. The embryos were transferred after 2 to 5 days, preferably 2 embryos, but 3 , in certain special cases. Surplus embryos were frozen on days $3,4,5$ or 6 post-collection. All patients undergoing embryo transfer used $2 \mathrm{mg}$ of oral estradiol valerate and $200 \mathrm{mg}$ of micronized vaginal progesterone every 8 hours or injectable $50 \mathrm{mg} / \mathrm{day}$, in the second phase, starting on the collection day. We used transdermal estradiol (Estradot $100^{\circledR}$ ), one adhesive daily, in the luteal phase, for patients who underwent agonist treatment for final maturation. We rarely used Ovidrel ${ }^{\circledR} 50$ mcg, on the day of ovum pick up, for patients at risk of OHSS who used agonist for maturation. Patients undergoing embryo transfer were submitted to estradiol, progesterone and chorionic gonadotropin ( $\beta \mathrm{HCG}$ ) dosing on day 7 post-transfer (TD7), and then progesterone and $\beta$ HCG 14 days, after embryo transfer, to assess chemical pregnancy. We used $\beta$ HCG $>25 \mathrm{mUI} / \mathrm{ml}$ as chemical pregnancy criteria. When pregnancy was confirmed, we performed endovaginal ultrasound after 10 (clinical pregnancy) and 20 days (for heart beat) after the last $\beta$ HCG dosing. We consider it to be an ongoing pregnancy, from 12 weeks on.

Estradiol concentration was measured in a Roche Modular Electrochemiluminescence device, the intra-individual variation was $18.1 \%$ and bias corresponded to $6.7 \%$.

Retrospective analysis of the serum estradiol levels on TD7 +/- 1 (TD7) and other data that composed the variables were extracted from Excel spreadsheet.

We assessed the mean serum estradiol concentration, progesterone and quantitative $\beta \mathrm{HCG}$ on the day stipulated above, although we did not evaluate progesterone ratio correlation in this publication (Table 1). According to age range ( $<35$ years, $35-39$ years, $>39$ years) we evaluated the following variables: mature eggs (M2) injected, embryos obtained, embryos transferred, day of transfer, percentage of transfers type 1, 2,3,4 (our private clinic classification based on: the number of embryos transferred, number of blastomeres in each embryo considering the TD regardless of the degree of fragmentation - Figure 1). In addition, we evaluated the mean estradiol and chorionic gonadotropin levels in $\mathrm{P}$ and NP groups.

We evaluated the TD7 estradiol concentration at different ranges (<200, 200-500 and $>500 \mathrm{pg} / \mathrm{ml}$ - Figure 2) and their relation to pregnancy prognosis. We also analyzed variables that could interfere with those concentrations and, in addition, we assessed P and NP by age group in patients up to 39 years of age. Figure 3 shows chemical, clinical, and ongoing pregnancy rates, in patients, according to estradiol concentrations. The addition of $E_{2}$ concentrations, above $900 \mathrm{pg} / \mathrm{ml}$, emphasizes the marker's prognostic value.

The T-test was used to evaluate differences between the groups, the Welch 's T-test was used for unequal sample sizes and Chi-square test with or without Yates correction and Fisher's exact test - to compare proportions. We applied Statistics for Excel and GraphPad software (QuickCalcs) to analyze the data. Significance for $p<0.05$.

\section{RESULTS}

One hundred and forty-three patients included, according to the selection criteria, took part in this study. According to the age range there were: 80 patients $<35$ years, 42 between 35 and 39 and $21>39$ years of age. Data analysis of the age groups in P and NP (Table 1 ) showed significant differences between the variables $E_{2}$ and $\beta H C G$ on TD7. We found statistical differences in patients up to 39 years old related to the following variables (Table 2 ): a. among patients with $E_{2}$ concentration $<200 \mathrm{pg} / \mathrm{ml}$, only $\beta$ HCG (10.05/0.312; $p=0.0247)$ between P and NP groups; b. in the group with $E_{2}$ concentrations from 200 to 500 $\mu \mathrm{g} / \mathrm{ml}$, embryos formed $(7.23 / 5.18 ; p=0.0143)$, embryos 
Table 1. ICSI. Variables associated with pregnancy likelihood in pregnant and non-pregnant women according to age groups (average).

\begin{tabular}{|c|c|c|c|c|c|c|c|c|c|}
\hline \multirow{2}{*}{ Variables } & \multicolumn{3}{|c|}{$<35$ years $(n=80)$} & \multicolumn{3}{|c|}{$35-39$ years $(n=42)$} & \multicolumn{3}{|c|}{$>39$ years $(n=21)$} \\
\hline & $\mathbf{P}$ & NP & $p$ & $\mathbf{P}$ & NP & $\boldsymbol{p}$ & $\mathbf{P}$ & NP & $\boldsymbol{p}$ \\
\hline Age & $30.64 \pm 31.05$ & $31.05 \pm 2.24$ & 0.2565 & $37.43 \pm 1.49$ & $36.88 \pm 1.36$ & 0.1192 & $40.8 \pm 1.16$ & $41.4 \pm 1.50$ & 0.1213 \\
\hline $\begin{array}{l}\text { Injected M2 } \\
\text { oocytes * }\end{array}$ & $10.73 \pm 5.34$ & $9.44 \pm 6.78$ & 0.1757 & $4.68 \pm 2.44$ & $8.03 \pm 5.07$ & 0.0103 & $5.00 \pm 1.09$ & $4.50 \pm 2.57$ & 0.3461 \\
\hline Embryos D3 & $8.11 \pm 4.73$ & $6.24 \pm 5.76$ & 0.0596 & $3.68 \pm 2.25$ & $5.51 \pm 4.54$ & 0.0772 & $3.41 \pm 1.01$ & $3.25 \pm 1.82$ & 0.4345 \\
\hline $\begin{array}{l}\text { Transferred } \\
\text { embryos }\end{array}$ & $2.71 \pm 0.73$ & $2.42 \pm 0.67$ & 0.0353 & $2.25 \pm 0.75$ & $2.34 \pm 0.78$ & 0.3516 & $2.80 \pm 0.74$ & $2.37 \pm 0.69$ & 0.1398 \\
\hline Day of transfer & $3.45 \pm 0.76$ & $3.44 \pm 0.81$ & 0.4889 & $3.37 \pm 0.85$ & $3.42 \pm 0.74$ & 0.4262 & $2.60 \pm 0.48$ & $3.13 \pm 1.10$ & 0.0989 \\
\hline Type of transfer & $1.20 \pm 0.41$ & $1.37 \pm 0.81$ & 0.1207 & $1.46 \pm 0.49$ & $1.57 \pm 0.68$ & 0.2997 & $1.40 \pm 0.48$ & $1.62 \pm 0.92$ & 0.3131 \\
\hline$E_{2}(p g / m l)$ in MLP & $835.26 \pm 724.93$ & $417.81 \pm 222.90$ & 0.0006 & $833.14 \pm 640.15$ & $434.61 \pm 415.52$ & 0.0118 & $841.04 \pm 351.15$ & $394.40 \pm 189.60$ & 0.0012 \\
\hline $\begin{array}{l}\text { BHCG }(\mathrm{mUI} / \mathrm{ml}) \\
\text { in MLP }\end{array}$ & $20.83 \pm 21.82$ & $0.70 \pm 1.59$ & 0.0001 & $21.49 \pm 22.25$ & $1.39 \pm 1.95$ & 0.002 & $16.6 \pm 9.60$ & $3.49 \pm 3.49$ & 0.0182 \\
\hline
\end{tabular}

* injected and rarely inseminated M2=mature E2=estradiol: $\mathrm{MLP}=$ mid-luteal phase (transfer day+7, TD7), T-Test=T-Test or Welch.

\begin{tabular}{|c|c|c|c|c|}
\hline & Very $\operatorname{good}(1) \#$ & $\operatorname{Good}(2)^{*}$ & Regular(3)** & $\operatorname{Bad}(4) * *$ \\
\hline D2 & $(\geq) 3 \mathrm{bl}(2)$ & $(\geq) 3 \mathrm{bl}(1)$ & $(\leq) 2 \mathrm{bl}$. & $\mathrm{PN}$ \\
\hline D3 & $(\geq) 6 \mathrm{bl}(2)$ & $(\geq) 6 \mathrm{bl}(1)$ & $4-5 \mathrm{bl}$. & $2-3 \mathrm{bl}$ \\
\hline D4 & Morula(2) & Morula(1) & $(\geq) 6$ bl e $<$ Morula & $(<) 6 \mathrm{bl}$ \\
\hline D5 & Blasto(2) & Blasto(1) & Morula & Cleaved embryos \\
\hline \multicolumn{3}{|c|}{$\begin{array}{l}\text { * } \quad \text { *nly one good embryo transferred } \\
\text { **Any number of embryos transferred } \\
\text { (< or >) Blastomeres number,lower or higher } \\
\text { \# Minimum of } 2 \text { embryos with good morphology } \\
\text { transferred } \\
\text { bl: blastomere, blasto= blastocist } \\
\text { PN : pronuclear }\end{array}$} & \multicolumn{2}{|c|}{$\begin{array}{l}\text { Classification } 1 \text { e 2: compatible cleavage day } \\
\text { Classification } 3 \text { : delay in the clivage } 24 \text { hours, } \geq \\
1 \text { embryo } \\
\text { Classification } 4 \text { : delay in the clivage } 48 \text { hours , } \geq \\
1 \text { embryo }\end{array}$} \\
\hline
\end{tabular}

Figure 1. Embryo transfer classification, fresh (number of embryos, number of blastomeres, transfer day) Humana 2

transferred (2.8/2.3; $p=0.0134)$ and $\beta$ HCG (10.59/0.79; $p<0.0001$ ) between $\mathrm{P}$ and NP groups; C. E2 concentration $>500 \mu \mathrm{g} / \mathrm{ml}$ group, transfer type $(1.18 / 1.47 ; p=0.0471)$, estradiol (1444/662.66; $p=0.0042)$, BHCG (19.30/1.12; $p<0.0001$ ) between $\mathrm{P}$ and NP groups [Figure 2 shows a statistically significant difference in mean estradiol levels in $P$ and NP ( $<35$ years, $835 / 417 ; p=0.0006),(35-39$ years $833 / 434 ; p=0.0118)$, ( $>39$ years, $841 / 394 ; p=0.0012)]$. Figure 3 shows chemical, clinical, and ongoing pregnancy rates within the three estradiol concentration ranges, and no difference between the groups $<200$ and 200$500 \mathrm{pg} / \mathrm{ml}(40 \% / 37.7 \%)$, but significant difference for $\mathrm{E}_{2}$ concentrations $>500 \mathrm{pg} / \mathrm{ml}(63.4 \%, p=0.0096)$, and a significant difference for the additional group $\geq 900 \mathrm{pg} /$ $\mathrm{ml}(95 \%, p<0.0001)$. These results enabled us to calculate the likelihood of chemical and clinical abortions in the three concentration ranges $(38.46 \%$ for the first 2 ranges versus $15.15 \%$ for concentrations $>500 \mathrm{pg} / \mathrm{ml}, p=0.0412$ and $5.26 \%$ for concentrations $>900 \mathrm{pg} / \mathrm{ml}, p=0.0105$. The
Pearson correlation coefficient for HCG and estradiol was $r=0.5108$.

\section{DISCUSSION}

Researchers in the field of assisted reproduction have been seeking to determine prognostic factors for success in IVF/ICSI for several years. Among these factors, serum estradiol concentrations in the follicular phase on the final maturation HCG administration day, and during the mid-luteal phase, has been extensively investigated, but mainly during the luteal phase, when the cycle can be evaluated, besides having the possibility of fixing this phase in the next cycle, if necessary.

The initial follicular phase was studied by Phelps et al. (1998) and Khalaf et al. (2000) who found a poor prognosis in pregnancy likelihood when estradiol levels on day 4 or 5 of the cycle were lower than $75 \mathrm{pg} / \mathrm{ml}$ in their first study and $50 \mathrm{pg} / \mathrm{ml}$ in the second; however, the studies were performed with agonists in a long-time frame protocol. 


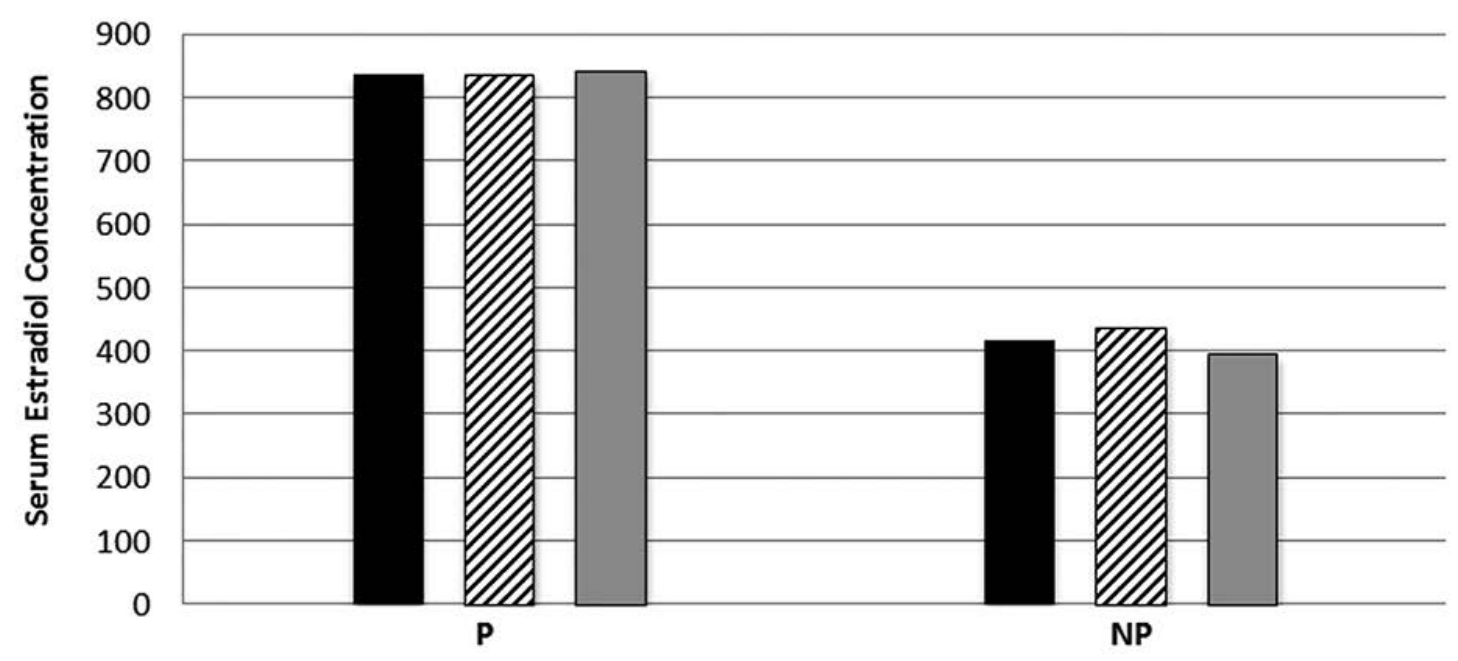

TD7 $=$ day of embryo transfer +7 ,

Figure 2. FIV/ICSI. Serum estradiol concentrations (picogram/ml) DT7, in pregnant women (P) and non-pregnant women (NP) according to three age ranges

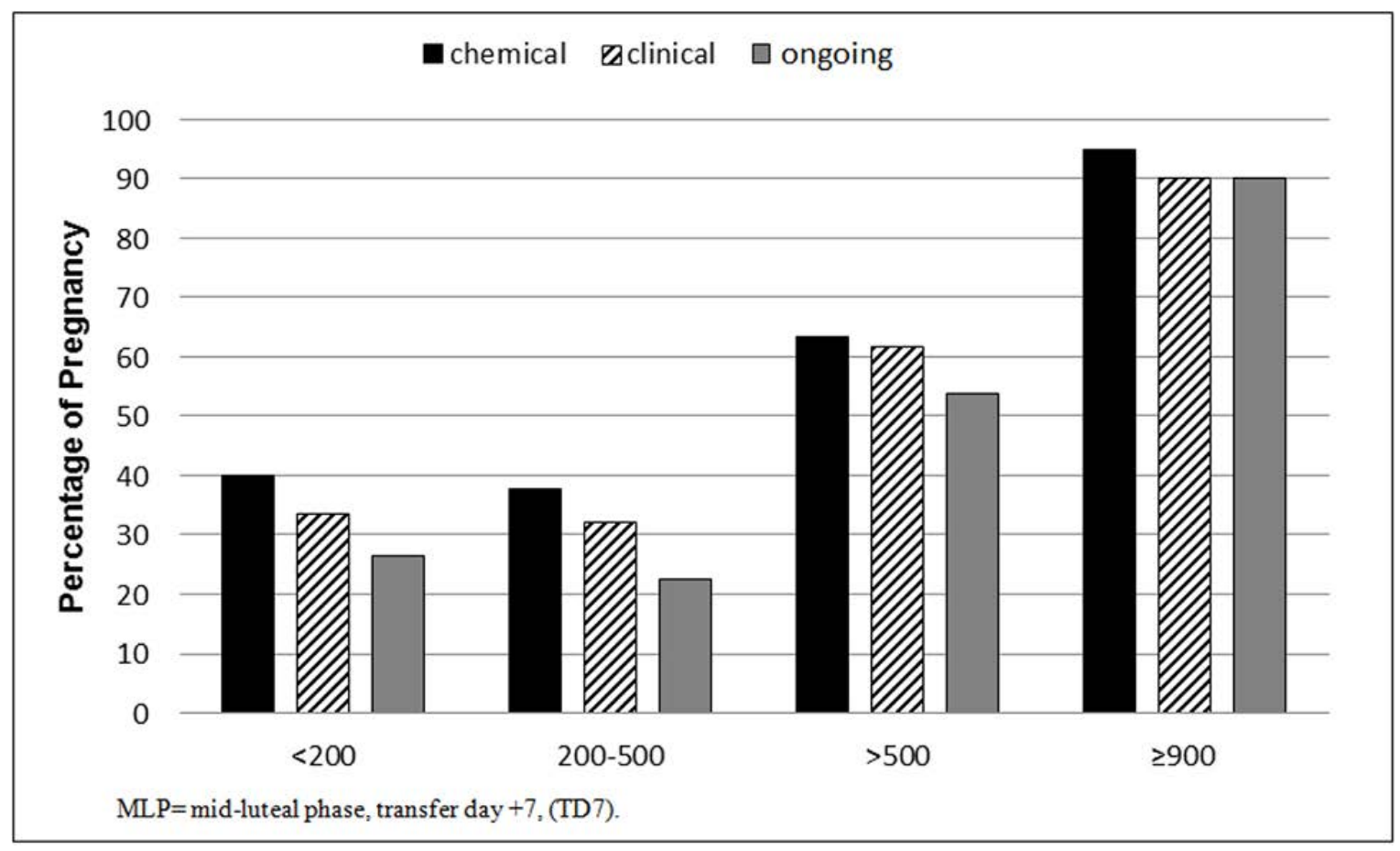

Figure 3. FIV/ICSI. Pregnancy rates in four different estradiol concentrations, picogram/ml, MLP, in patients $\leq 39$ years

On the day of final maturation of induced cycles (Erzincan et al., 2014), before or after HCG administration, Huang et al. (2015), found no difference in pregnancy likelihood between the estradiol concentration groups $<2000,2000-$ 4000 and $>4000 \mathrm{pg} / \mathrm{ml}$.

Several authors have reported higher levels of estradiol in the mid-luteal phase of conceptive cycles, both for natural (Baird et al., 1997), or hyper stimulated ones, in patients undergoing IVF/ICSI, and having used HCG for final maturation (Balasch et al., 1995; Greb et al., 2004; Ganesh et al., 2008; Moini et al., 2011), without exogenous estradiol administration. Our results confirm those authors' findings, in a very clear and significant way, and it can be seen in Figure 2 (in correlation to age groups). The $E_{2}$ concentration averages ranged from 831 to 841 $\mathrm{pg} / \mathrm{ml}$, in the $P$ group, and 394 to $434 \mathrm{pg} / \mathrm{ml}$ in the NP group $(p<0.001)$ (age groups). Beckers et al. (2003) carried out a prospective study regarding IVF/ICSI, and 


\begin{tabular}{|c|c|c|c|c|c|c|c|c|c|}
\hline \multirow{2}{*}{ Variables } & \multicolumn{3}{|c|}{$<200 \mathrm{pg} / \mathrm{ml}$} & \multicolumn{3}{|c|}{$200-500 \mathrm{pg} / \mathrm{ml}$} & \multicolumn{3}{|c|}{$>500 \mathrm{pg} / \mathrm{ml}$} \\
\hline & $\mathbf{P}$ & NP & $\boldsymbol{p}$ & $\mathbf{P}$ & NP & $\boldsymbol{p}$ & $\mathbf{P}$ & NP & p \\
\hline Age & $30.66 \pm 5.18$ & $32.77 \pm 3.61$ & 0.2014 & $33.65 \pm 3.88$ & $33.30 \pm 3.39$ & 0.3697 & $32.27 \pm 3.49$ & $33.68 \pm 3.49$ & 0.1013 \\
\hline Collected oocytes & $12.83 \pm 6.43$ & $14.22 \pm 7.28$ & 0.3649 & $15.75 \pm 12.45$ & $10 \pm 6.90$ & 0.0195 & $11.60 \pm 7.81$ & $14.53 \pm 8.04$ & 0.1069 \\
\hline $\begin{array}{l}\text { Injected M2 } \\
\text { oocytes* }\end{array}$ & $7.57 \pm 4.13$ & $10.00 \pm 7.26$ & 0.2420 & $10.25 \pm 7.04$ & $7.84 \pm 6.38$ & 0.0891 & $8.57 \pm 4.48$ & $9.57 \pm 5.15$ & 0.2372 \\
\hline Embryos D3 & $4.50 \pm 2.21$ & $7.22 \pm 6.92$ & 0.2012 & $7.23 \pm 5.26$ & $5.18 \pm 4.60$ & 0.0143 & $6.57 \pm 3.87$ & $6.94 \pm 5.47$ & 0.3904 \\
\hline $\begin{array}{l}\text { Transferred } \\
\text { embryos }\end{array}$ & $2.66 \pm 0.47$ & $2.44 \pm 0.68$ & 0.2651 & $2.80 \pm 0.74$ & $2.30 \pm 0.75$ & 0.0134 & $2.45 \pm 0.78$ & $2.47 \pm 0.68$ & 0.4654 \\
\hline Day of transfer & $3.33 \pm 0.47$ & $3.44 \pm 0.49$ & 0.3467 & $3.35 \pm 0.72$ & $3.24 \pm 0.77$ & 0.4096 & $3.52 \pm 0.84$ & $3.72 \pm 0.80$ & 0.2199 \\
\hline Type of transfer** & $1.66 \pm 0.74$ & $1.33 \pm 0.47$ & 0.1707 & $1.25 \pm 0.62$ & $1.48 \pm 1.01$ & 0.1827 & $1.18 \pm 0.45$ & $1.47 \pm 0.75$ & 0.0471 \\
\hline E2 $(\mathrm{pg} / \mathrm{ml})$ in MLP & $132.42 \pm 52.23$ & $105.11 \pm 53.55$ & 0.1897 & $356.16 \pm 86.08$ & $325.17 \pm 77.34$ & 0.0968 & $1444.98 \pm 1185.60$ & $662.66 \pm 119.04$ & 0.0042 \\
\hline $\begin{array}{l}\beta H C G(m U I / m l) \\
\text { in MLP }\end{array}$ & $10.05 \pm 8.44$ & $0.312 \pm 0.40$ & 0.0247 & $10.59 \pm 8.98$ & $0.79 \pm 1.43$ & 0.0001 & $19.30 \pm 11.54$ & $1.12 \pm 2.09$ & 0.0001 \\
\hline
\end{tabular}

$\mathrm{E}_{2}=$ estradiol, $\mathrm{MLP}=$ mid-luteal phase (transfer day+7, TD7), $\beta \mathrm{HCG}=$ chorionic gonadotropin, * injected or inseminated, ** Human embryo transfer classification 2 .

compared cycles with 150 IU/day of recombinant gonadotropin associated with antagonist, to block pituitary activity. Three groups were classified for the final maturation: 1-recombinant HCG 250 mcg (r-HCG), 2-recombinant LH $1 \mathrm{mg}(\mathrm{r}-\mathrm{LH})$ and 3-triptorelin $2 \mathrm{mg}$. No patient used drugs in the luteal phase. They evaluated the hormonal profile during the luteal phase and the duration of such phase. They reported that the luteal phase duration was longer with r-HCG (13 days), and the lowest duration was with triptorelin (9 days). $E_{2}$ and progesterone profiles were reasonable with HCG and poor with r-LH and triptorelin. Pregnancy rates were extremely low. Their study showed the need for progesterone replacement in all IVF/ICSI cycles, in which pituitary activity was blocked. The use of $E_{2}$ in daily doses of 4 to $6 \mathrm{mg} /$ day to improve the luteal phase is a controversial topic. Fatemi et al. (2007), Ceyhan et al. (2008), Aghahosseini et al. (2011), Lin et al. (2013) and Engmann et al. (2008) in randomized studies, reported no benefit stemming from the administration of $E_{2}$ in a dose of $4 \mathrm{mg} /$ day. Other authors (Drakakis et al., 2007; Jee et al., 2010; Kwon et al., 2013; Gizzo et al., 2014; Zhang et al., 2015) reported higher pregnancy likelihoods with the administration of $\mathrm{E}_{2}$, especially $6 \mathrm{mg} /$ day of estradiol valerate. Higher pregnancy rates were also found in some studies involving estradiol patches, always associated with vaginal or injectable progesterone. There is controversy surrounding the use of $E_{2}$ in the luteal phase when $\mathrm{GnRH}$ agonist is used for final maturation, but the administration of oral or transdermal estradiol hormones for those patients should not be questioned. Authors such as DiLuigi et al. (2010) recommended the maintenance of estradiol levels higher than $200 \mathrm{pg} / \mathrm{ml}$ in the luteal phase, associated with injectable progesterone. Our data confirms such authors' opinion. However, $\mathrm{E}_{2}$ levels at or below $500 \mathrm{pg} / \mathrm{ml}$, showed no difference in the likelihood of pregnancy, even though our patients received aggressive $E_{2}$ replacement in the luteal phase, associated with injectable progesterone, and apparently, a patient with $100 \mathrm{pg} / \mathrm{ml} \mathrm{E}_{2}$ on TD7 had the same likelihood of another patient with $500 \mathrm{pg} / \mathrm{ml}$ (Figure 3 ). We did not find any studies that investigated age group correlation to serum estradiol concentration. Our study showed no difference in estradiol concentration and age group, but there was a significant difference in those 3 age ranges between the $P$ and NP groups (Table 1 ), showing that the production of estradiol was not altered by age, but only by the capacity of the lutein cells to respond to the production of trophoblast $\beta \mathrm{HCG}$ in a qualitative and quantitative way. Elements that may interfere with estradiol concentrations, apart from $\beta$ HCG, have not been discussed in this paper but we plan to do it in another publication.

The variables analyzed in Tables 1 and 2 show data related to pregnancy likelihood. P and NP groups, according to the age group, showed that the analyzed variables, except $\beta H C G$ and $E_{2}$, did not present statistical difference, including mean age, and embryo transfer type. For example, the type of embryo transfer was numerically lower in the $P$ group for the 3 age ranges $(1.20 / 1.37,1.46 / 1.57$, $1.40 / 1.62)$, but such differences were not statistically significant. The remarkable statistical difference of $E_{2}$ followed by $\beta H C G$ in the 3 age groups, suggests a positive correlation between the two hormones, although the correlation factor had presented a positive correlation of $p=0.5108$, a moderate one only.

Few authors, such as Fujimoto et al. (2002), studied estradiol concentration ranges to determine the chances of pregnancy in IVF/ICSI procedures related to the use of agonist in a long scheme. This group classified $E_{2}$ concentrations into: $<100,100-500$ and $>500 \mathrm{pg} / \mathrm{ml}$, on TD7, and they found pregnancy rates of $13.3 \%, 26.8 \%$ and $36.3 \%$, respectively. In addition, they offered a second attempt of IVF in cases of failure for patients in the group with $\mathrm{E}_{2}<100 \mathrm{pg} / \mathrm{ml}$. In this second cycle, they fixed the luteal phase with 3000 IU HCG on transfer days 1, 4 and 7. Such approach increased estradiol and progesterone levels, and pregnancy rates increased to $31.7 \%$, against $13.7 \%$, in the group that used only injectable progesterone.

We assessed the likelihoods of chemical, clinical, and ongoing pregnancies. We found similar pregnancy rates in the groups $<200$ and $200-500$, but higher in the groups $>500 \mathrm{pg} / \mathrm{ml}, p=0.0096$ and $\geq 900 \mathrm{pg} / \mathrm{ml}, p<0.0001$, in chemical, clinical and ongoing pregnancies (Figure 3 ), confirming the findings of Balasch et al. (1995). Another data for further investigation is the low abortion rate, in the group with $E_{2}$ levels $>500 \mathrm{pg} / \mathrm{ml}$ and $>900 \mathrm{pg} / \mathrm{ml}$, compared to the group of $E_{2} \leq 500 \mathrm{pg} / \mathrm{ml}(15.15 \%$ versus $38.46 \%, p=0.0412$ and $5.26 \%$ versus $38.46 \%, p=0.0105)$.

\section{CONCLUSION}

The present study shows the prognostic value of $E_{2}$ in the mid-luteal phase, TD7, for chemical, clinical, and ongoing pregnancies. The $\mathrm{E}_{2}$ concentrations obtained, suggesting it had a positive correlation with $\beta H C G$ levels. 


\section{CONFLICT OF INTEREST}

No conflict of interest has been declared.

\section{ACKNOWLEDGEMENT}

We are very thankful for the collaboration of: Lidia Regina Zanatta de Oliveira Castro who assisted on the bibliographical research; Mirian Rodrigues Borges and Ellen Glaucia de Souza Lima, for the tables and charts' review and Kleber Santiago and Carlos Eduardo Oliveira for the English text review.

\section{Corresponding author:}

Rodopiano de Souza Florêncio

Humana Medicina Reprodutiva

Goiania, GO - Brazil

E-mail: drodopianoflorencio@gmail.com

\section{REFERENCES}

Aghahosseini $M$, Aleyassin A, Khodaverdi S, Esfahani $F$, Mohammadbeigi R, Movahedi S, Kord Valeshabad A, Mahdavi A, Fallahi P, Shabani P, Rezaeeian Z, Khodaverdi M. Estradiol supplementation during the luteal phase in poor responder patients undergoing in vitro fertilization: a randomized clinical trial. J Assist Reprod Genet. 2011;28:78590. PMID: 21720788 DOI: $10.1007 /$ s10815-011-9595-8

Aktan E, Bozkurt K, Ozer D, Yucebilgin S, Karadadas N, Bilgin $O$. The effect of mid-luteal estradiol level on the outcome of ICSI-ET cycles. Arch Gynecol Obstet. 2004;269:134-8. PMID: 12928936 DOI: 10.1007/s00404-003-0533-6

Baird DD, Wilcox AJ, Weinberg CR, Kamel F, McConnaughey DR, Musey PI, Collins DC. Preimplantation hormonal differences between the conception and non-conception menstrual cycles of 32 normal women. Hum Reprod. 1997;12:2607-13. PMID: 9455822 DOI: 10.1093/humrep/12.12.2607

Balasch J, Creus M, Fábregues F, Carmona F, Casamitjana R, Peñarrubia J, Rivera F, Vanrell JA. Hormonal profiles in successful and unsuccessful implantation in IVF-ET after combined GnRH agonist/gonadotropin treatment for superovulation and hCG luteal support. Gynecol Endocrinol. 1995;9:51-8. PMID: 7793300 DOI: 10.3109/09513599509160191

Beckers NG, Macklon NS, Eijkemans MJ, Ludwig M, Felberbaum RE, Diedrich K, Bustion S, Loumaye $E$, Fauser BC. Nonsupplemented luteal phase characteristics after the administration of recombinant human chorionic gonadotropin, recombinant luteinizing hormone, or gonadotropin-releasing hormone $(\mathrm{GnRH})$ agonist to induce final oocyte maturation in in vitro fertilization patients after ovarian stimulation with recombinant follicle-stimulating hormone and GnRH antagonist cotreatment. J Clin Endocrinol Metab. 2003;88:4186-92. PMID: 12970285 DOI: $10.1210 /$ jc. $2002-021953$

Ceyhan ST, Basaran M, Kemal Duru N, Yilmaz A, Göktolga $U$, Baser I. Use of luteal estrogen supplementation in normal responder patients treated with fixed multidose $\mathrm{GnRH}$ antagonist: a prospective randomized controlled study. Fertil Steril. 2008;89:1827-30. PMID: 18054930 DOI: 10.1016/j.fertnstert.2007.08.029
Csemiczky G, Wramsby H, Landgren BM. Luteal phase oestradiol and progesterone levels are stronger predictors than follicular phase follicle stimulating hormone for the outcome of in-vitro fertilization treatment in women with tubal infertility. Hum Reprod. 1996;11:2396-9. PMID: 8981118 DOI: $10.1093 / o x f o r d j o u r n a l s . h u m r e p . a 019122$

DiLuigi AJ, Engmann L, Schmidt DW, Maier DB, Nulsen JC, Benadiva CA. Gonadotropin-releasing hormone agonist to induce final oocyte maturation prevents the development of ovarian hyperstimulation syndrome in high-risk patients and leads to improved clinical outcomes compared with coasting. Fertil Steril. 2010;94:1111-4. PMID: 20074722 DOI: $10.1016 /$ j.fertnstert.2009.10.034

Drakakis $\mathrm{P}$, Loutradis D, Vomvolaki E, Stefanidis K, Kiapekou E, Anagnostou E, Anastasiadou K, Milingos S, Antsaklis A. Luteal estrogen supplementation in stimulated cycles may improve the pregnancy rate in patients undergoing in vitro fertilization/intracytoplasmic sperm injection-embryo transfer. Gynecol Endocrinol. 2007;23:645-52. PMID: 17999276 DOI: $10.1080 / 09513590701664923$

Engmann L, DiLuigi A, Schmidt D, Benadiva C, Maier $D$, Nulsen J. The effect of luteal phase vaginal estradiol supplementation on the success of in vitro fertilization treatment: a prospective randomized study. Fertil Steril. 2008;89:554-61. PMID: 17678651 DOI: $10.1016 /$ j.fertnstert.2007.04.006

Erzincan SG, Esmer AC, Baysal B. Does the estradiol level on the day of human chorionic gonadotropin administration predict the clinical outcome of controlled ovarian hyperstimulation? Clin Exp Obstet Gynecol. 2014;41:709-12. PMID: 25551969

Fatemi HM, Kolibianakis EM, Camus M, Tournaye H, Donoso $P$, Papanikolaou E, Devroey P. Addition of estradiol to progesterone for luteal supplementation in patients stimulated with GnRH antagonist/rFSH for IVF: a randomized controlled trial. Hum Reprod. 2006;21:2628-32. DOI: 10.1093/humrep/del117

Fatemi HM, Camus M, Kolibianakis EM, Tournaye $\mathrm{H}$, Papanikolaou EG, Donoso P, Devroey P. The luteal phase of recombinant follicle-stimulating hormone/gonadotropin-releasing hormone antagonist in vitro fertilization cycles during supplementation with progesterone or progesterone and estradiol. Fertil Steril. 2007;87:504-8. PMID: 17140572 DOI: $10.1016 /$ j.fertnstert.2006.07.1521

Friedler S, Zimerman A, Schachter M, Raziel A, Strassburger $D$, Ron El R. The midluteal decline in serum estradiol levels is drastic but not deleterious for implantation after in vitro fertilization and embryo transfer in patients with normal or high responses. Fertil Steril. 2005;83:54-60. PMID: 15652887 DOI: $10.1016 /$ j.fertnstert.2004.08.017

Fujimoto A, Osuga Y, Fujiwara T, Yano T, Tsutsumi O, Momoeda M, Kugu K, Koga K, Morita Y, Wada O, Taketani Y. Human chorionic gonadotropin combined with progesterone for luteal support improves pregnancy rate in patients with low late-midluteal estradiol levels in IVF cycles. J Assist Reprod Genet. 2002;19:550-4. PMID: 12503886 DOI: 10.1023/A: 1021207014429 
Ganesh A, Goswami S, Chattopadhyay R, Chakraborty C, Chaudhury K, Chakravarty BN. Luteal phase estradiol level: a potential predictive marker for successful pregnancy in in vitro fertilization/intracytoplasmic sperm injection. Fertil Steril. 2008;91:1018-22. PMID: 18359023 DOI: 10.1016/j.fertnstert.2008.01.074

Gelbaya TA, Kyrgiou M, Tsoumpou I, Nardo LG. The use of estradiol for luteal phase support in in vitro fertilization/intracytoplasmic sperm injection cycles: a systematic review and meta-analysis. Fertil Steril. 2008;90:2116-25. PMID: 18178194 DOI: $10.1016 /$ j.fertnstert.2007.10.053

Gizzo S, Andrisani A, Esposito F, Noventa M, Di Gangi S, Angioni S, Litta P, Gangemi M, Nardelli GB. Which luteal phase support is better for each IVF stimulation protocol to achieve the highest pregnancy rate? A superiority randomized clinical trial. Gynecol Endocrinol. 2014;30:902-8. PMID: 25268567 DOI: 10.3109/09513590.2014.964638

Gorkemli H, Ak D, Akyurek C, Aktan M, Duman S. Comparison of pregnancy outcomes of progesterone or progesterone + estradiol for luteal phase support in ICSI-ET cycles. Gynecol Obstet Invest. 2004;58:140-4. PMID: 15205566 DOI: $10.1159 / 000079115$

Greb RR, Lettmann N, Sonntag B, Schüring AN, von Otte $S$, Kiesel L. Enhanced oestradiol secretion briefly after embryo transfer in conception cycles from IVF. Reprod Biomed Online. 2004;9:271-8. PMID: 15353074 DOI: $10.1016 / \mathrm{S} 1472-6483(10) 62141-4$

Huang N, Situ B, Chen X, Liu J, Yan P, Kang X, Kong S, Huang M. Meta-analysis of estradiol for luteal phase support in in vitro fertilization/intracytoplasmic sperm injection. Fertil Steril. 2015;103:367-73.e5. PMID: 25492682 DOI: $10.1016 /$ j.fertnstert.2014.10.029

Hung Yu Ng E, Shu Biu Yeung W, Yee Lan Lau E, Wai Ki So $W$, Chung Ho P. A rapid decline in serum oestradiol concentrations around the mid-luteal phase had no adverse effect on outcome in 763 assisted reproduction cycles. Hum Reprod. 2000;15:1903-8. PMID: 10966983 DOI: 10.1093/humrep/15.9.1903

Hutchinson-Williams KA, Lunenfeld B, Diamond MP, Lavy G, Boyers SP, DeCherney AH. Human chorionic gonadotropin, estradiol, and progesterone profiles in conception and nonconception cycles in an in vitro fertilization program. Fertil Steril. 1989;52:441-5. PMID: 2776898 DOI: 10.1016/S0015-0282(16)60915-9

Jee BC, Suh CS, Kim SH, Kim YB, Moon SY. Effects of estradiol supplementation during the luteal phase of in vitro fertilization cycles: a meta-analysis. Fertil Steril. 2010;93:428-36. PMID: 19342034 DOI: 10.1016/j.fertnstert.2009.02.033

Khalaf Y, Taylor A, Braude P. Low serum estradiol concentrations after five days of controlled ovarian hyperstimulation for in vitro fertilization are associated with poor outcome. Fertil Steril. 2000;74:63-6. PMID: 10899498 DOI: $10.1016 /$ S0015-0282(00)00569-0

Kutlusoy F, Guler I, Erdem M, Erdem A, Bozkurt N, Biberoglu $\mathrm{EH}$, Biberoglu KO. Luteal phase support with estrogen in addition to progesterone increases pregnancy rates in in vitro fertilization cycles with poor response to gonadotropins. Gynecol Endocrinol. 2014;30:363-6. PMID: 24517720 DOI: $10.3109 / 09513590.2014 .887065$
Kwon SK, Kim CH, Lee $\mathrm{KH}$, Jeon IK, Ahn JW, Kim SH, Chae HD, Kang BM. Luteal estradiol supplementation in gonadotropin-releasing hormone antagonist cycles for infertile patients in vitro fertilization. Clin Exp Reprod Med. 2013;40:131-4. PMID: 24179871 DOI: 10.5653/cerm.2013.40.3.131

Lenton EA, Sulaiman R, Sobowale O, Cooke ID. The human menstrual cycle: plasma concentrations of prolactin, $\mathrm{LH}, \mathrm{FSH}$, oestradiol and progesterone in conceiving and non-conceiving women. J Reprod Fertil. 1982;65:131-9. PMID: 6804627 DOI: 10.1530/jrf.0.0650131

Lin $\mathrm{H}$, Li Y, Li L, Wang W, Zhang Q, Chen X, Yang D. Oral oestradiol supplementation as luteal support in IVF/ICSI cycles: a prospective, randomized controlled study. Eur J Obstet Gynecol Reprod Biol. 2013;167:171-5. PMID: 23287635 DOI: $10.1016 /$ j.ejogrb.2012.11.026

Lukaszuk K, Liss J, Lukaszuk M, Maj B. Optimization of estradiol supplementation during the luteal phase improves the pregnancy rate in women undergoing in vitro fertilization-embryo transfer cycles. Fertil Steril. 2005;83:1372-6. PMID: 15866571 DOI: 10.1016/j.fertnstert.2004.11.055

Moini A, Zadeh Modarress S, Amirchaghmaghi E, Mirghavam N, Khafri S, Reza Akhoond M, Salman Yazdi R. The effect of adding oral oestradiol to progesterone as luteal phase support in ART cycles - a randomized controlled study. Arch Med Sci. 2011;7:112-6. PMID: 22291742 DOI: 10.5114/aoms.2011.20613

Phelps JY, Levine AS, Hickman TN, Zacur HA, Wallach EE, Hinton EL. Day 4 estradiol levels predict pregnancy success in women undergoing controlled ovarian hyperstimulation for IVF. Fertil Steril. 1998;69:1015-9. PMID: 9627286 DOI: $10.1016 /$ S0015-0282(98)00059-4

Serna J, Cholquevilque JL, Cela V, Martínez-Salazar J, Requena A, Garcia-Velasco JA. Estradiol supplementation during the luteal phase of IVF-ICSI patients: a randomized, controlled trial. Fertil Steril. 2008;90:2190-5. PMID: 18191847 DOI: $10.1016 /$ j.fertnstert.2007.10.021

Sharara FI. Value of mid-luteal oestradiol level: prognostic implications for IVF. Hum Reprod. 2001;16:2476. DOI: 10.1093/humrep/16.11.2476

Zegers-Hochschild F, Altieri E. Luteal estrogen is not required for the establishment of pregnancy in the human. J Assist Reprod Genet. 1995;12:224-8. PMID: 8520190 DOI: $10.1007 / B F 02211803$

Zhang XM, Lv F, Wang $P$, Huang XM, Liu KF, Pan Y, Dong $\mathrm{NJ}$, Ji YR, She H, Hu R. Estrogen supplementation to progesterone as luteal phase support in patients undergoing in vitro fertilization: systematic review and meta-analysis. Medicine (Baltimore). 2015;94:e459. PMID: 25715250 DOI: $10.1097 /$ MD.0000000000000459 